Dos Cadernos dos Alunos 



\section{Concurso Literário do Colégio de Aplicação}

Juçara Benvenuti*

Em prosseguimento à ação de extensão C oncurso Literário realizada pelo Departamento de Comunicação do Colégio de A plicação (CA p), nos anos 2007 e 2008, celebramos o aniversário da escola, no primeiro semestre do ano letivo, com as edições comemorativas anuais. O concurso é aberto à comunidade, nas categorias mirim, infanto-juvenil, juvenil e adulto, nas modalidades crônica, poesia ou charge e busca a valorização da memória afetiva da escola. Toda a comunidade é convidada a participar: alunos das séries iniciais, do Projeto Amora, de 7ạ e 8ạ séries e do Ensino M édio, professores, funcionários, pais e ex-alunos.

0 estímulo à produção escrita e o registro dessas memórias da comunidade escolar do Colégio fazem parte dos objetivos do projeto. Os critérios analisados pelas comissões julgadoras são: adequação ao tema, identificação com a modalidade escoIhida, criatividade e originalidade, respeitadas as características intrínsecas de cada categoria.

No ano de 2007, as comissões julgadoras foram constituídas pelos seguintes professores: Andrea Czardonay Perrot, Gláucia R egina R aposo de Souza, I vana K átia de Souza Ferreira, L aura Vellinho Corso, Luciana H ahn Brum, M árcia I vana de L ima e Silva, R ita de Cássia Cavalvante, Sandra M ara Appel K ischloski e Tadeu Rossato Bisognin.

No ano de 2008, foram os seguintes: Adalberto Breier, Gláucia R egina R aposo de Souza, I vana K átia de Souza Ferreira,

Professora de Língua Portuguesa do CAp/UFRGS, coordenadora do Projeto EJA/ PROEJA. M estre em Teoria da Literatura pela PU CRS. D outoranda do Instituto de L etras da UFRGS. E-mail: jucarabe@ cap.ufrgs.br 
M árcia I vana de L ima e Silva, M arlon M ello de Almeida, Sandra M ara Appel Kischloski, Simone Vaccaro Fogazzi e Tadeu Rossato Bisognin.

A seguir os textos premiados em 2007:

$\mathrm{N}$ a categoria infanto-juvenil, na modalidade charge e na poesia: R icardo M atheus A costa de Barros, da 8a série, com 0 texto Diga não à discriminação e C olégio de A plicação.

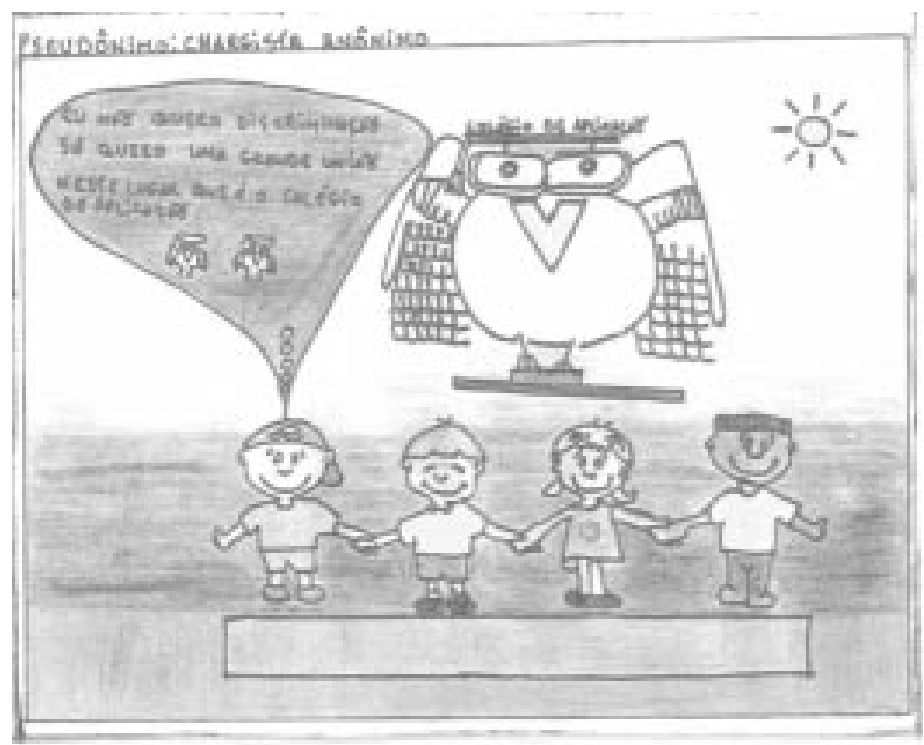

Colégio de Aplicação

N o Aplicação você descobre

O seu cantinho predileto

D esde a sala de aula

A té um lugar secreto

No Aplicação você tem

O s seus melhores momentos

0 bate-papo com os amigos

$\mathrm{M}$ as sempre rola

U m contratempo.

No meu colégio adorado

Sou sempre bem tratado! 
Saudade terei

D e cada recreio,

D e cada aula

E de cada bagunça.

De um colega

Dizendo: Professora,

M e tocaram uma laranja!

Professora, tiraram os parafusos

Da minha classe!

Colégio de Aplicação

Q ue um pedaço de mim traz,

Saiba que no meu coração,

Jamais ficarás para trás.

$\mathrm{N}$ a categoria infanto-juvenil, na modalidade crônica narrativa, o destaque ficou para a aluna Alexsandra M. M oura, da turma Amora I A, com o trabalho 0 J oão-debarro que se tornou arquiteto.

\section{O J oão de Barro que se tornou Arquiteto}

E ra uma vez um J oão de Barro que queria aprender como construir uma casa diferente para morar, pois a sua casinha somente tinha uma peça, e como ele havia se desentendido com a sua companheira não tinha como ficar junto. Então, ele resolveu conversar com outros pássaros da Floresta do M orro Santana. O primeiro pássaro que ele conversou foi com seu grande amigo Bem-te-vi. E perguntou-lhe:

- Diga-me uma coisa, Bem-te-vi, como é que eu posso fazer uma casa diferente?

O Bem-te-vi pensou, pensou e disse:

- Sei lá, pois eu somente me preocupo em construir o meu ninho na Estação da Primavera no alto de uma árvore. E sugeriu o Bem-te-vi:

- Q uem sabe tu falas com o nosso amigo Sabiá, pois ele sempre está por aí agitando e fazendo festa na floresta. 
Então, o J oão de Barro foi à procura do Sabiá. Voou para o alto de uma árvore cheia de frutos e lá encontrou os seus amigos sabiás comendo frutinhas e contando muitas histórias. Perguntou-Ihes:

- Amigos, como faço para construir uma casa diferente e bem resistente? O Sabiá mais velho respondeu:

- João de Barro, tu tens que contratar alguém que tenha bom conhecimento de como construir um.

- M as com quem tu achas que eu devo conversar?

O Sabiá respondeu:

- Eu sugiro que tu vás até o campo e, procura o escoteiro e desobediente Q uero-quero, que ele saberá te orientar e indicar quem poderá te ajudar.

Então, o J oão de Barro foi ao campo falar com o Q ueroquero. Chegando lá viu que os Q uero-queros estavam muito agitados, pois eles estavam em guerra com uma matilha de cães e nesta luta feroz eles venceram e expulsaram os cães que haviam invadido o território deles.

O João de Barro se aproximou e disse:

- Com licença compadre Q uero-quero? Posso falar um instante contigo? E o Q uero-quero respondeu:

- Claro, amigo J oão de Barro, seja bem vindo ao meu território. Em que posso servir? R espondeu o Q uero-quero. 0 J oão de Barro perguntou-lhe:

- Tu tens ideia de com quem eu posso me orientar para construir uma casa diferente? $\mathrm{O} Q \mathrm{Q}$ uero-quero respondeu rapidamente.

- N ão tenhas dúvidas, vai falar com o mestre dos mestres, Professor Coruja ele é o mais sábio pássaro da Floresta.

O J oão de Barro se despediu do Q uero-quero e foi procurar o professor Coruja. Chegando a casa dele viu que ele estava repousando. M esmo assim arriscou acordá-lo e o chamou:

- Professor Coruja, tu poderias me ajudar? 0 professor olhou para o J oão de Barro, e viu que ele estava bastante abatido e triste. Com toda aquela paciência de mestre, disse:

- Amigo João de Barro, vejo que tu estás muito preocupado, conta-me o que está acontecendo? E o J oão de Barro disse: 
- Pois é meu amigo Coruja, a minha vida não está boa, me desentendi com a minha companheira e resolvi sair de casa. 0 Professor Coruja não se conteve e começou a dar risadas e disse:

- M eu amigo, volta pra casa e te reconcilia com a tua companheira, pois ela estará de braços abertos te esperando. Pois, a grande razão de tu viveres é a tua companheira. Faça as pazes com ela e não seja teimoso.

O João de Barro disse:

- Professor Coruja, eu queria construir uma casa diferente para dar de presente para a minha companheira, como faço? 0 mestre Coruja olhou para J oão de Barro e disse:

- Vá ao encontro da tua companheira e convida-a para vir ao Colégio A plicação para aprender com os professores como se constrói uma casa. Pois ali tu aprenderás muita coisa e leva também os teus filhos, eles terão um futuro brilhante.

O João de Barro ficou muito entusiasmado com as sugestões do mestre Coruja que resolveu colocar as ideias em prática. Fez as pazes com a companheira, e foram morar com os filhos no Colégio. Todos os dias eles ficavam atentamente na janela escutando os ensinamentos dos professores e foi assim que o João de Barro aprendeu a fazer sua casinha com duas peças, e a família foi crescendo, crescendo e agora são várias casas que eles têm no Colégio Aplicação e não pretendem sair dali tão cedo.

$\mathrm{N}$ a categoria juvenil, na modalidade poesia, o primeiro lugar ficou com a aluna Aline Porto Fernandes da Silva, do 3ำ ano do Ensino M édio, com o trabalho Falando do A plicação.

\section{Falando do Aplicação}

I magino quantos

Aqui já estudaram

O u virão a fazêlo

N este colégio que me encanta,

Pelo tanto que cresci

Aqui e ali 
Ao passar pelos corredores

Avivam-se na memória

Tantas lembranças:

Passar pela CACA

O uvir o sino tocar,

$\mathrm{N}$ ib e D eep Purple,

$\mathrm{N}$ ão posso me atrasar.

Colégio que Ihe fará

Acreditar em

A mizade sincera,

Inocência eterna,

E essencialmente,

Q ue toda pergunta é válida.

Colégio que gera

I ncompreendidas emoções,

Que me faz ter pressa

De realizar sonhos

Tão almejados,

Proporcionados pelo esforço

De professores, funcionários, diretores.

A plicação,

D e tudo apenas uma certeza:

$\mathrm{N}$ ão há melhor lugar

Pra se estudar.

$\mathrm{N}$ a categoria adulto, na modalidade crônica narrativa, o texto premiado foi da professora A na Paula S. M artins, com o título $A$ arte do descarrego de sentimentos não muito nobres.

A arte do descarrego de sentimentos não muito nobres

Sabe aqueles dias em que o tempo se arrasta? Aqueles dias em que você deveria ter ficado enterrado na sua cama ao invés de ter se levantado? Justamente porque lá no fundo algo Ihe enviava a informação de que este não era o seu dia... 
Sabe aqueles dias em que nada dá certo? N em mesmo uma coisa muito simples... Pois é... este foi o meu dia do avesso.

o dia de hoje marca o início de um novo ciclo de vida para mim, é um dia muito importante porque eu tenho aguardado por isto há meses. Eis que hoje é meu primeiro de trabalho no CAp. U m dia feliz!!! Sigo eu sorridente saltitando pelas calçadas...

Aí eu ouço uma voz longínqua: "- A corda Rafa!!! Bem vinda ao mundo real criatura, pois hoje também é o seu dia do avesso."

Eu me belisco... mas ... foi em vão... não adiantou... hojeé realmente o meu dia do avesso...

Sete horas da manhã e começa a chover torrencialmente na capital dos Pampas, água para todo lado. O lho no relógio, estou em tempo, não vou chegar atrasada no primeiro dia de trabalho apesar da chuva, e nem molhada, pois hoje eu trouxe a minha sombrinha. $\mathrm{H}$ ahahaha... ledo engano... estou eu no corredor de ônibus, parada cheia, e eis que passa um ônibus correndo na via alagada. R esultado? U m banho de água cor típica do Guaíba em todas as pessoas que compartilhavam do dito abrigo comigo. Pros ares a minha aura de alegria e presença de espírito zen, proferi a todos os pulmões uma palavra nada bonita. Eu não vi o nome da linha do ônibus, nem daria devido à velocidade que 0 motorista passou pelo corredor.

A onda de água suja produzida pelo ônibus em movimento veloz me atingiu em cheio. Se serve de consolo... ainda bem que eu estava com a boca fechada.

Fiquei alguns segundos fazendo o levantamento dos estragos... bolsa e pasta com meu material da aula encharcadas, roupa igualmente encharcada, saia indiana e blusa branca de linha tricô. O brigada ao insight que tive esta manhã que me levou a prender meus longos cabelos em um coque. 0 inesperado banho produziu um lindo mosaico de sujeirinhas de todo tipo em minhas pernas. Que legal! Arte pós-moderna em meu corpo!

Chegou meu ônibus, que bom ainda estou no horário. 0 trajeto até meu destino é curto, sentei no fundo do ônibus e 
comecei a me secar com meus mágicos e muito úteis lenços de papel folhas duplas super absorventes. Sequei os óculos e retoquei o batom. Pelo menos algo em mim tinha que estar em ordem no primeiro dia de professora no CAp! Chego no colégio e vou direto para o banheiro. Viva as duas pilhas de tolhas de papel sobre a bancada!!! Confiro o relógio, alguns minutos de sobra, ufa... Penso: Por que aqui não tem aquelas maquininhas D ry $\mathrm{H}$ ands que tem no aeroporto e nos shoppings? Por quê? Por quê?

N a portaria, no corredor e na sala de aula eu faço cara de paisagem para os olhares dos colegas e alunos que devem estar pensando: "Como ela conseguiu se molhar assim?" A pós explicações sobre meu estado molhado iniciei minha primeira aula.

U ma coisa pelo menos deu certo neste dia. Cheguei em tempo no campus e ministrei minha primeira aula sem ter chegado atrasada por causa da chuva.

Q uando terminaram as aulas da manhã o sol era luminoso e imperava num céu azul como se a tempestade de logo cedo que alagou ruas e encharcou pessoas tivesse sido um mero pesadelo.

Já perto de casa passei no super, comprei latinhas de cerveja, Polar [porque é daqui!]. Q ueria comemorar, afinal hoje é um dia importante para mim, apesar dos contratempos. Cheguei em casa e ouvi a mesma voz a proferir com desdenho: "- A corda Rafa!!! H oje é seu dia do avesso, esqueceu criatura???" Q ue ótimo!!!

Pensei, pensei, pensei... devia haver uma forma de descarregar esta energia trancada aqui dentro, esta raiva incontida, produto deste dia do avesso... Q uando se está assim neste estado, parece que só o ato de estraçalhar algo numa parede tem o poder de acalmar os ânimos...

Fui até a geladeira, peguei as latinhas de cerveja Polar, me diriji até o meu banheiro e iniciei o ritual de descarrego de sentimentos não muito nobres com o arremesso de latinhas de cerveja no box. Ah... fui tomada por uma leveza súbita na alma ao fim do ritual... 
Ainda bem que existem os boxes de banheiro e cerveja em lata para você poder descarregar seus sentimentos, digamos assim... não muito nobres.

Q ue beleza, pude deitar minha cabeça no travesseiro macio e dormir o sono dos anjos, com o desejo de que o dia do avesso não tenha bis.

A seguir os textos premiados em 2008

$\mathrm{N}$ a categoria mirim, na modalidade charge, o primeiro lugar ficou com o aluno Mauro Luciano dos Santos Adolfo Júnior da turma Alfa 3, com o trabalho U ma Escola boa pra Cachorro!

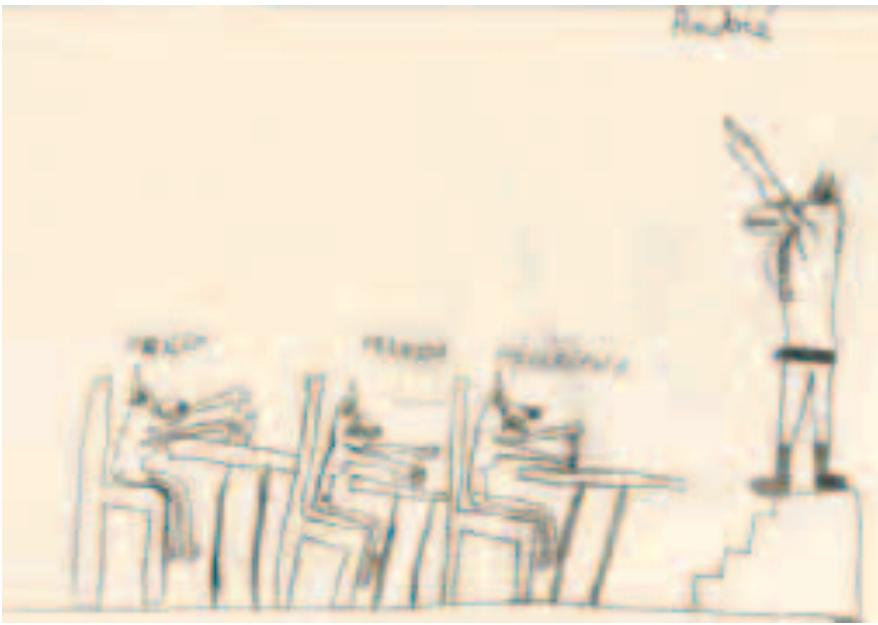

$\mathrm{N}$ a categoria mirim, na modalidade crônica narrativa, o texto premiado foi da aluna A na Clara Sast Grassi da turma Alfa 3, com o título U m Bichinho Diferente.

\section{U m Bichinho Diferente}

Era uma vez um bichinho diferente, por quê?

Porque ele se alimentava de perguntas. 0 nome dele era João, mas o chamavam de Bichinho Curioso.

U m dia ele foi parar em um colégio, chamado A plicação. 
As alunas Flávia e A na Clara passavam por ali, quando viram um bichinho cantando. Elas se assustaram e perguntaram:

- Qual o seu nome bicho falante?

- M eu nome é J oão, mas me chamam de Bichinho Curioso.

E ele perguntou:

- Qual os seus nomes?

$\mathrm{E}$ as duas meninas se apresentaram.

Então Ana perguntou:

- Por que te chamam de Bichinho Curioso?

E ele respondeu:

- Porquemealimento de perguntas. Estou morto de fome!

E Flávia falou:

- Tive uma ideia!

Então Ana perguntou:

- Qual?

Aí Flávia disse:

- Lá na sala todo mundo tem várias perguntas, então ele não vai passar fome.

E o bicho falou:

- Vamos lá!

E

Fim!!!

$\mathrm{N}$ a categoria mirim, na modalidade poesia, o primeiro lugar foi para a aluna da turma Alfa 4 Valéria Sofia Bagatini, com 0 trabalho Trilha do CAp.

\section{Trilha do CAP}

Valéria Sofia Bagatini

$\mathrm{Na}$ alfa I foi pura diversão

meu coração não parou

de brilhar na trilha a vida

de aprender a escrever e a ler. 
$\mathrm{Na}$ alfa II foi pura diversão

meu coração não parou

de brilhar na trilha da vida

e de aprender a desenhar e a sonhar.

$\mathrm{Na}$ alfa III foi pura diversão

meu coração não parou

de brilhar na trilha da vida

de aprender a multiplicar e a brilhar.

$\mathrm{Na}$ alfa $\mathrm{VI}$ foi pura diversão

meu coração não parou

de brilhar na trilha da vida

de aprender a dividir e a fazer poesia.

$\mathrm{N}$ a categoria infanto-juvenil, na modalidade crônica narrativa, o texto premiado em primeiro lugar A C onferência dos pássaros foi da aluna Alexsandra M. M oura, da turma Amora II.

\section{A conferência dos pássaros}

H á um pouco mais de uma década, aconteceu uma grande conferência dos pássaros na Floresta do M orro Santana, afinal algo extraordinário estava acontecendo na planície e, merecia uma atenção especial dos moradores da floresta.

Por sua vez, o Q uero-Quero sempre atento e vigilante a tudo que acontece a seu redor, percebeu que havia um movimento bastante grande nas redondezas e, foi verificar do que se tratava. O lhou, olhou e não entendeu nada do que significava todo aquele movimento, e resolveu consultar o seu grande amigo de longa data o João de Barro. E perguntou-lhe:

- Meu amigo João de Barro tu sabes o que está acontecendo na Planície? $\mathrm{H}$ á um grande movimento de pessoas e novas construções acontecendo. 
O João de Barro respondeu:

- Infelizmente, meu caro amigo, eu não tenho a mínima ideia do que realmente está acorrendo ali.

- E o Q uero-Q uero perguntou para o J oão de Barro. Q uem será que pode saber alguma coisa?

O João de Barro, respondeu rapidamente.

- Eu acho que tu deves consultar o nosso amigo Bem-tevi, ele tem muitos amigos na Floresta. E os dois amigos estavam confabulando e veja quem apareceu... o Bem-te-vi... pois, ele estava bastante preocupado, logo foi dizendo:

- Vocês sabem o que está acontecendo na Planície? E o Q uero-Q uero respondeu:

- Pois meu amigo, nós iríamos procurá-lo justamente para saber se tens alguma ideia do que estão construindo na Planície. $\mathrm{O} u$ se tu sabes quem pode nos informar sobre 0 assunto.

0 Bem-te-vi respondeu: go Sabiá.

- Eu acho que nós devemos consultar o nosso alegre ami-

Então os amigos foram à procura do Sabiá, enquanto 0 Q uero-Q uero montava guarda, o J oão de Barro e o Bem-te-vi voaram para alto de uma árvore cheia de frutos, e lá encontrou os seus amigos Sabiás comendo frutinhas e contando muitas histórias. Perguntaram-Ihe:

- A migos vocês sabem o que significa a construção na Planície? E o Sabiá mais velho disse:

- Eu não sei, mas sugiro que se faça uma consulta a nossa grande amiga Saracura, pois todos os dias ela faz uma grande algazarra na Floresta.

E lá se foram os amigos a cada momento mais preocupados, afinal algo estava acontecendo e, os pássaros ainda não sabiam o que estava ocorrendo. Ao encontrar a Saracura, o J oão de Barro perguntou:

- Comadre Saracura, tu sabes o que estão construindo na Planície? A Saracura respondeu:

- Parece que é um Colégio, eu sei que o M estre Coruja está envolvido diretamente no Projeto, pois ele acompanha diariamente a obra. 
O Bem-te-vi respondeu:

- Finalmente alguém tem uma noção do que está ocorrendo na planície.

E o Quero-Quero se manifestou:

- Pois, agora que temos alguma ideia do que está ocorrendo, sugiro irmos ao encontro do mestre Coruja, pois ele é o mais Sábio pássaro da floresta e, todos aprenderam a respeitá-lo, admirá-lo. Ele é um exemplo de sabedoria e dedicação. E os amigos chegando a casa dele viram que ele estava repousando. M esmo assim os amigos arriscaram acordá-lo e o chamaram:

- Professor Coruja, estamos muito preocupados com a construção que está ocorrendo na planície. A comadre Saracura falou que o mestre sabe o que realmente está acontecendo.

Com toda aquela paciência de mestre, disse:

- N ão precisam ficar preocupados, pois ali estão construindo o novo Colégio de A plicação. E acrescentou:

- Temos a oportunidade de participar destegrande empreendimento. Para isto deveremos fazer uma grande Conferência com todos os pássaros do Morro Santana e discutir as tarefas que temos que fazer no Colégio.

E os amigos ali reunidos montaram uma estratégia, de como fariam a grande conferência dos pássaros da Floresta. E a data foi marcada.

O grande dia chegou, e ficou decidido que o J oão de Barro seria o principal morador do Prédio e, que ele repassaria para os demais pássaros o conhecimento e as informações recebidas dos professores. O Quero-Quero seria responsável pela segurança do Colégio. E, por fim, o M estre Coruja seria o Professor no Colégio de A plicação.

E também pela sua intelectualidade ele foi escolhido, por unanimidade, o pássaro símbolo do Colégio de A plicação.

Fim.

$N$ a categoria adulto, na modalidade crônica narrativa, o texto premiado em primeiro lugar foi de um ex-aluno do CAp Francisco Goulart Jahn, com o título A plicação de 1968. 


\section{A plicação de 1968}

Prepare o seu coração pras coisas que eu vou contar, eu venho do Aplicação e posso até agradar!

Ainda não é meio-dia. M eu grupo sai mais cedo, porque já terminamos o trabalho de M atemática. No bar da Filosofia, estão pintando faixas para a passeata. J ogo dedo-bola com o Tibério. Ele já disse que chamar de fingerball este futebol que se joga com dedo indicador na bolinha de gude é render-se ao imperialismo. Ele é pernambucano e foi expulso da faculdade de direito de lá, depois das eleições para o centro acadêmico. Eu sei, mas ele não sabe que eu sei, que ele é da AP (Ação Popular). Só podia ser mesmo, com este sotaque de seminarista. $O$ Zé L oguércio chega e senta para falar com o Tibério. Acho que ele também é da AP. Diz que combinou com o Vieira (presidente do DCE) como vão ser os comícios-relâmpago. Sempre três ao mesmo tempo, só pra fazer a D O PS e o Choque não saberem para que lado ir. U m na Rodoviária, outro na Praça da Matriz e o maior na Praça Quinze.

- O Iha ali os Branca, ele diz, indicando o I co e o Goulart; (e canta baixinho) branca, branca, branca, leon, leon, leon, pum. (agora sussurra para nós):

- Dizem que esta semana chega a metralhadora e organizam um grupo de guerrilha no Morro da Polícia.

- Eles são uma dissidência da VPR (vanguarda popular revolucionária), disse o Tibério.

- O I co tem um irmão no A plicação, um piá, o N eisinho e o Goulart sempre me chamam de primo por causa de nosso sobrenome - penso eu, em voz alta.

É terça-feira. N ão tem aula pela tarde no A plicação. D ia de nossa reunião de célula, hoje na casa da camarada Tatiana. O s pais dela são professores na U FR GS e acham que estamos fazendo reuniões da U M ESPA. D as 14 às 18 h falamos sobre os ensinamentos de J. Posadas, discípulo e herdeiro autêntico do ideário de Trotzky.

A revolução é permanente e iminente. Vamos convocar uma greve geral mundial! 
O camarada Carlos (nome de guerra, é óbvio, pois o exercício da clandestinidade faz parte do projeto revolucionário), secretário da célula, faz um informe do editorial do último número do Frente O perária - publicação quinzenal do Partido O perário R evolucionário - Seção Brasileira da 43 Internacional. N ão existem motivos para temer os discos-voadores objetos de diversas notícias de aparições recentes. Se eles chegam aqui vindos de um planeta distante e nós ainda não chegamos no planeta deles é porque eles já atingiram um estágio de evolução posterior ao nosso. O bviamente, isto significa que já são socialistas. Eles vêm até nós para conferir e, de forma discreta, auxiliar na construção de um mundo socialista. Procuram os revolucionários autênticos e logo fazem contato conosco, os verdadeiros trotzkystas.

A prova de química não foi fácil. N ão consigo prestar atenção no conteúdo da aula da professora Solange. Fico com o pensamento paralisado no conteúdo do decote e da roupa dela. Ela tem olhos verdes. Cabelos pretos, agora não muito compridos porque ela cortou um pouco. Chega até os ombros. Seios grandes e firmes. U m corpo insinuante em curvas e volumes. Ela falou volumes na última aula e esta palavra não me sai mais da cabeça. Ela fica linda com o vestido branco e verde estampado com ramos e flores. Combina com os olhos que ficam ainda mais luminosos. L embro-me de duas aulas em que ela está com este vestido e também na semana passada, quando encontrei-a na frente da Engenharia. Eu poderia ter-Ihe dito que em uma sociedade socialista a química - como as demais ciências - estará a serviço da coletividade e não do lucro burguês. Seria uma forma de aproximação madura, politicamente... mas ao invés disto, só disse besteiras, fiquei até meio gago. Ela tem vinte e quatro ou vinte e cinco anos. Eu quatorze. I sto não quer dizer nada! D aqui dois meses, eu farei quinze. Afinal, muitos casais tem dez anos de diferença de idade. U m colega babaca diz que, se eu confessar meu desejo, ela vai me responder: "Que coisa mais querida!" I sso seria inaceitável.

No final da reunião, falamos de assuntos gerais do nosso cotidiano. Falei que não conseguia entender o significado do 
número de Avogadro e por isso havia ido mal na prova de química. 0 camarada Gildo lembra que o revolucionário tem sempre um bom desempenho na escola e no trabalho, mesmo quando o mundo ainda se encontra em seu patamar capitalista. Propôs-se a ensinar-me. A final ele já está no terceiro científico e é um dos que já foi procurado pelo Cursinho Pré- vestibular. O fereceram até dinheiro para ele assistir aulas lá... mal sabem que ele é da Q uarta! E le seria capaz de denunciar a oferta. Só porque ele deverá ter um dos primeiros lugares na M edicina, ficam atrás dele. Seria uma exposição perigosa, por isso a célula decide que ele simplesmente descartará qualquer interesse no cursinho, mesmo que eles ofereçam dinheiro que poderia ser usado para mandar um representante nosso no Congresso da U BES.

6,02 vezes 10 na 23 na casa do camarada Gildo. A mãe dele acaba de nos trazer um lanche: bolo de chocolate e café com leite. Ele lembra que todas as mães têm uma preocupação atávica com a alimentação dos filhos. Lembro que isso não vai mudar com a revolução. De repente um fedor de peido. Mudo, mas intenso.

- Camarada! O que é isso camarada? - pergunto.

- Desculpe, eu não sinto cheiro - ele se justifica.

- Mas de que adianta ter esse nariz, então?

- Pois é! U m verdadeiro nariz idish... mas não sou fanático.

$\mathrm{N}$ ada fanático. $\mathrm{N}$ ada fanáticos. D escendente de alemão do Clube de Tiro em M ontenegro na casa de neto de fugitivos do progrom na $R$ ússia. E nós aqui, enfrentado Avogadro e comungando os ideais trotzkistas.

Só uma dúvida: como conseguiremos levar adiante uma greve geral mundial? Cada célula tem de fazer o seu trabalho, é a resposta. Precisamos cumprir nosso papel histórico. Como acontece na França, o movimento estudantil é a vanguarda histórica que com seu trabalho de conscientização trata de transformar as reivindicações transitórias em reivindicações permanentes. Por exemplo, exigimos a melhora das condições de ensino e denunciamos que em nosso país se gasta mais com a alimentação dos 
animais do exército do que com salário de professores. Após, conscientizamos a população de que com este governo e com este regime isto não vai mudar. 0 Exército está a serviço da repressão à R evolução Proletária e garante a manutenção da propriedade privada e por isto ele é considerado uma prioridade neste regime. A cultura e a educação somente serão prioridade dentro de uma sociedade socialista, na qual cada um produz de acordo com sua capacidade, para que cada um consuma de acordo com a sua necessidade.

Estou em minha casa. Termino de jantar e digo para os meus pais que já vou dormir, estou muito cansado. N o meu quarto coloco a jaqueta na cadeira, tiro meu tênis topa-tudo (tipo guidis, verde exército, melhor dizendo, verde Araguaia) e me cubro vestido. Fico lendo Sidarta de $\mathrm{H}$ erman $\mathrm{H}$ esse até escutar que eles fecharam a porta do quarto. O lho no relógio: 11 da noite. Q ue bom que meu irmão está em São Paulo. A turma dele visita a exposição Bienal. Ele está fora da Quarta, desde a viagem para M ontevideo e não me explica o porquê. Ainda por cima faz a cara mais desagradável do mundo, quando Ihe chamo de camarada Boris. L eio até as 11 e meia. L evanto silenciosamente. Calço o tênis, pego a jaqueta. Saio pé ante pé, respirando baixinho até o corredor. D esço dois andares a pé pela escada para não fazer barulho. Chamo o elevador para descer os sete andares que ainda faltam. Cumprimento o porteiro da noite com uma forte naturalidade. A plico minha teoria do otimismo positivo: ele está imaginando que compro um $\mathrm{M}$ inister para minha mãe e depois ele se esquece de não me ver entrar.

Caminho rápido pela Lima e Silva até a Venâncio Aires. Coloquei a jaqueta e estou suando... Passos rápidos. U m revolucionário tem objetivo. $\mathrm{N}$ ão é qualquer bêbado que vai me atrapalhar. U ma prostituta na esquina. Melhor nem olhar... ando ligeiro. Se houver algum movimento estranho, corro. N ão é que eu tenha medo. Eu preciso chegar. N essa hora tem pouca gente na rua. D obro na Augusto Pestana. Chego na casa do camarada Carlos. Bato na porta. N inguém aparece. $M$ as tem luz acesa no quarto de cima. Finalmente ele me abre a porta. Estão 
todos lá em cima. O plano já está pronto. R apidamente me explicam: vamos dormir imediatamente e amanhã cumpriremos as ações planejadas pelo CR (comitê regional). 0 despertador toca às $4 \mathrm{~h}$. L evanto e faço 20 polichinelos e 20 apoios de frente. U m revolucionário precisa ter saúde! U ma xícara de café preto forte e saímos em dois grupos. Eu faço parte do segundo. Por questões de segurança, desconheço o destino do primeiro grupo.

Chegamos na esquina da Ramiro Barcelos. Estou com a camarada Tatiana e o camarada Carlos. Acho que ela gosta dele. Ele é duro. U m verdadeiro revolucionário. Me diz bem chateado que seu pai é um burguês incorrigível e por isso, infelizmente, precisa ser fuzilado depois da revolução. Ainda bem que meu pai, não. U m fusca cor de vinho está parado. N os aproximamos. O camarada Carlos aproxima-se do motorista e Ihe diz:

- Está livre?

- Desde 1917! - é a resposta.

Entramos no banco de trás, eu e a camarada Tatiana. Já está ali alguém... é o camarada Ciro, do Comitê R egional, um de nossos dirigentes!

O camarada Carlos senta-se ao lado do motorista. O fusca vai até a Av. M auá e estaciona ao lado do prédio dos Correios. A camarada Tatiana e o camarada Ciro simulam ser namorados e vão ficar na esquina. Se ouvirmos um apito muito fininho, sumiremos cada um para um lado. Eu e o camarada Carlos pixamos o prédio do Museu de Arte: ABAIXO A DITADURA E VIVA A REVOLUÇÃO SOCIALISTA. Acrescentamos VIVA TR OTZKY. Foice, martelo e um 4 em cima. Jogamos fora o spray e as luvas e voltamos para o fusca. Por enquanto, tudo perfeito. São 5h15. D aqui a pouco vai amanhecer. Vamos para a segunda atividade planejada. Chegamos no bairro Cristal. Estacionamos em uma praça. U m homem está sentado em um banco e pisca um isqueiro quatro vezes. Ele se aproxima e diz para o motorista: os documentos estão em baixo do quarto banco, uma sacola branca. E se afasta. O camarada Ciro e a camarada Tatiana se sentam em um banco. O camarada Carlos vai até o banco onde está a sacola e a traz para o fuca. São cerca de duzentos jornais Frente 
O perária. $\mathrm{N}$ a capa, no campo superior direito, em destaque, em vermelho, a estampa da foice e martelo recobertos pelo algarismo 4. Vamos distribuir para os primeiros operários que chegam entre as $6 \mathrm{~h} 30$ e as $6 \mathrm{~h} 50$. Às $7 \mathrm{~h}$ chega o grupo de segurança, e aí já precisamos estar longe. Eu tenho uns 100 FO s comigo, camarada Tatiana outros tantos. Cada um vai por um lado. Com um apito começamos a distribuir. Com dois apitos suspendemos a entrega e nos escondemos e com três fugimos cada um para um lado. Estou no portão distribuindo. D ou dois ou três para cada um e digo para darem para os seus colegas. Ainda tenho uns 10 FO comigo, quando alguém lá de dentro grita:

- Ei, guri! Larguei os que ainda tinha nas mãos de alguém que chegava. Corri até a curva do estaleiro, me recompus e fui caminhando até a pracinha. $\mathrm{N}$ a outra quadra, o fusca me faz um sinal de farol. Vou caminhando rápido até lá. Já estão todos dentro do carro que arranca rapidamente em direção ao centro. D esço na esquina da Lima e Silva e caminho rápido para casa.

0 porteiro me olha com a testa franzida:

- Teu pai e tua mãe já andaram no Pronto Socorro, nas delegacias e nos hospitais. Te procuraram a noite toda!

Respiro fundo, ponho a chave na porta e entro. M inha mãe sentada no sofá, lágrimas escorrendo pelo rosto balbucia alguma coisa como "M eu D eus! M inha N ossa Senhora"...

Paro no meio do tapete. M eu pai de pé, caminha para um lado e para o outro.

- Eu peço desculpas. Pensei que vocês iam ficar dormindo! Digo baixo, engasgado. Vou para o quarto, pego minha pasta e volto para a sala.

- Desculpas mais uma vez. Tchau! Tenho de ir para o colégio.

$\mathrm{N}$ a aula, muito sono. A professora de $\mathrm{H}$ istória anuncia que vamos preparar o debate de final de ano. Q uase acordo com a notícia:

- Então vamos discutir Capitalismo versus Socialismo! diz o Bicó. Ela logo responde: 
- N ão! Julgamento de $\mathrm{N}$ apoleão. A direção mudou o programa... Prossegue em tom mais baixo. Estou tão cansado que não consigo nem protestar direito.

Chego em casa. M eu irmão mais velho está na mesa e conversa com minha mãe. Passo direto para o banheiro, mas o escuto reclamando que não digo nem alô para ele. M inha mãe logo explica:

- Ele teve a primeira noite de homem ontem e está bem cansado...

Esta solução está de bom tamanho, pensei sorrindo comigo mesmo. $\mathrm{N}$ ão gosto de mentir para ela. 

Editoração e impressão:

$$
\begin{aligned}
& \text { S) } \\
& \text { UFRES } \\
& \text { GRÁFICA } \\
& \begin{array}{l}
\text { DA UNIVERSIDADE FEDERAL } \\
\text { DO RIO GRANDE DO SUL }
\end{array}
\end{aligned}
$$

